\title{
História, perspectivas e contradições no Ensino Médio Integrado na Rede Federal de Educação Profissional
}

\author{
History, perspectives and contradictions in high school integrated in the \\ federal network of professional education
}

Recebido: 12/06/2018 | Revisado: 18/12/2020 | Aceito: 18/11/2020 | Publicado: 16/06/2021

\section{Elane Nardotto Rios}

ORCID: https://orcid.org/0000-0002-47068972

Instituto Federal de Educação, Ciência e Tecnologia da Bahia

E-mail: elanenardoto@yahoo.com.br

Como citar: RIOS, E. N.; História, perspectivas e contradições no Ensino Médio Integrado na rede federal de Educação Profissional. Revista Brasileira da Educação Profissional e Tecnológica [S.I.], v. 1, n. 20, p 1-11. e7389. jun. 2021. ISSN 2447-1801.

This work is licensed under a Creative Commons Attribution 4.0 Unported License.

\begin{abstract}
Resumo
Este artigo traz como objetivo a apresentação de dados referentes ao ensino médio integrado da Rede Federal de Educação Profissional considerando suas implicações históricas e até mesmo contraditórias. Inicia-se esse debate com a Lei no 11.892/2008 que criou a Rede Federal de Educação Profissional, Científica e Tecnológica em território nacional, para, em seguida, abordar o percurso histórico da constituição da Educação Profissional no Brasil desde a Colônia até a atualidade. Traz, ainda, as diretrizes do ensino politécnico compreendido como princípio organizador do currículo numa inter-relação entre área profissional e área propedêutica. Por fim, apresenta problematizações e questões referentes ao modo como a integração no Ensino Médio vem se configurando após o Decreto n. 5.154/04 e a promulgação da Lei 11.892/08. De base metodológica bibliográfica, traz resultados concernentes às condições de construção da Educação Profissional no Brasil, concluindo que outras pesquisas balizadas no campo empírico poderão trazer resultados mais efetivos acerca do funcionamento, na dimensão prática, do que está proposto na Lei 11.892/2008 e nas diretrizes nacionais para o Ensino Médio Integrado da Rede Federal.
\end{abstract}

Palavras-chave: Educação Profissional; Integração; Ensino Médio; Rede Federal.

\begin{abstract}
This article aims to present data on integrated secondary education from the Federal Network of Professional Education considering its historical and even contradictory implications. This debate begins with Law 11,892 / 2008 that created the Federal Network for Professional, Scientific and Technological Education in the national territory, to, then address the historical path of the constitution of Professional Education in Brazil since Colony until today. It also brings the guidelines of polytechnic education understood as the organizing principle of the curriculum in an interrelation between the professional area and the propaedeutic area. Finally, it presents problematizations and questions regarding the way in which integration in high school has been taking shape after Decree n. 5,154 / 04 and the enactment of Law 11,892 / 08. With bibliographic methodological basis, it brings results concerning the conditions of construction of Professional Education in Brazil, concluding that other research based on the empirical field may bring more effective results about the functioning, in the practical dimension, of what is proposed in Law 11.892 / 2008 and in national guidelines for Integrated Secondary Education of the Federal Network.
\end{abstract}

Keywords: Professional Education; Integration; High school; Federal Network. 


\section{INTRODUÇÃO}

Há doze anos que a Lei n. 11.892/2008 está em vigor e se consolidando nos diferentes campi da Rede Federal de Educação Profissional e Tecnológica, Rede IF, do território nacional. Com base nisso, este artigo traz pressupostos acerca do Ensino Médio Integrado cujo objetivo, segundo a referida lei, é garantir a formação humana na organização curricular considerando os documentos e diretrizes elaborados para constituir um currículo em que as disciplinas técnicas dialoguem com as propedêuticas. Para isso, uma retomada no percurso histórico da constituição da Educação Profissional no Brasil desde a Colônia, perpassando o Império, a República, até a atualidade.

Nesse percurso histórico, é nítido como a classe trabalhadora sempre esteve excluída de uma formação humanística haja vista os currículos profissionais se voltarem, apenas, para o mercado de trabalho. Com a integração, há uma inclusão na formação crítica, cultural, filosófica e sociológica das pessoas que acessam a Rede Federal Profissional, embora nem sempre tenha sido dessa forma. Conforme foi dito, com o Decreto n. 5.154/04 e a promulgação da Lei 11.892/08 assistimos a essa inclusão que, à sua vez, está se consolidando.

Tal debate se pautou numa base metodológica bibliográfica, já que revisei leis, documentos, diretrizes e bibliografia para contextualizar e problematizar às condições de construção da Educação Profissional no Brasil. Desse modo, não trouxe conclusões "acabadas", e sim, questões anunciadas para que pesquisas posteriores, sobretudo, aquelas voltadas para o campo empírico, para a relação de ensinoaprendizagem, compreendam e analisem como essa integração está ocorrendo na prática.

\section{PERCURSO HISTÓRICO DA EDUCAÇÃO PROFISSIONAL NO BRASIL}

Discutir sobre a Educação Profissional no Brasil está relacionada a um modo de produção capitalista iniciado desde a colonização em oposição a um modo de produção "comunista primitivo" presentificado nas sociedades indígenas. Formar para a profissão, implicou, desde aquela época, uma construção conflituosa na sociedade brasileira levando em conta a formação desigual na esfera social marcada por processos predatórios na atividade colonial em que classes trabalhavam em prol de outra num processo de escravidão para alguns.

Nesse período, o que se observa é que não ocorria um processo educativo em ligação com o trabalho profissional, e sim, uma ação dos Jesuítas que, mesmo de forma assistemática, ensinava aos indígenas algumas técnicas de agricultura, além de ofícios como carpintaria, sapataria e tecelagem. Já os filhos das classes dirigentes e os filhos dos colonos recebiam uma educação de caráter intelectual, até mesmo porque o Brasil produzia e exportava produtos primários, não sendo necessário 
qualificar e intelectualizar os trabalhadores braçais. Ou seja, já data dessa época, uma divisão trabalho, sendo o trabalho manual destinado aos escravos.

Com a expulsão da Companhia de Jesus ocorreu uma necessidade de reorganizar o ensino e entre os objetivos do Marques de Pombal estavam: trazer a educação para o controle do Estado, secularizar e padronizar o currículo. Nesse âmbito, havia uma defesa para uma educação da juventude voltada para obtenção de conhecimentos sobre agricultura e comércio e no currículo do Colégio Real dos Nobres tinha disciplinas de formação para a náutica, a arquitetura militar e civil; e desenho.

Com a mudança da família real portuguesa para o Brasil, entre as iniciativas na área de educação, há a criação de cursos para a formação técnica nas áreas de economia, química, agricultura e desenho técnico. Nessa época a discriminação da educação profissionalizante quase se tornou uma regra no Brasil haja vista o artigo 124 do Projeto da Constituição prever que o Império deveria construir estabelecimentos de modo a garantir a catequese dos índios com vistas a uma educação religiosa e industrial.

Ainda nos meados do século XIX, se observa uma preocupação com 0 processo educativo para crianças abandonadas nos abrigos, resultando no ensino das primeiras letras e encaminhamento para as oficinas públicas. Uma educação profissional marcadamente direcionada aqueles que não tinham muita opção, apenas as atividades braçais que, por sua vez, não eram feitas por todos os brasileiros.

Da passagem do Império para a República, até a Primeira Guerra Mundial, há um incremento nas atividades industriais e, em 1909, tem-se a criação, pelo Governo Federal, de 19 Escolas de Aprendizes e Artífices subordinadas ao Ministério da Agricultura, Indústria e Comércio e destinadas a oferecer ensino profissional primário gratuito aos desvalidos, a classe mais pobre da sociedade, sendo o primeiro ensaio para se formalizar a Educação Profissional1.

No século $X X$, ainda se observa a propagação da racionalização do trabalho materializada no Taylorismo, Fordismo e Toyotismo2 para os cursos de aperfeiçoamento, cursos técnicos e tecnológicos a fim de responder às demandas da industrialização, ocorrendo uma separação entre a concepção e a execução das tarefas no trabalho industrial. Uma qualificação voltada para a instrução meramente operacional sem um cuidado com o desenvolvimento intelectual, crítico e humano do trabalhador. Naquela época, os trabalhadores brasileiros não tinham uma formação específica para atender ao Mercado Industrial e 0 Estado recorreu à institucionalização de agências profissionalizantes paralelas ao sistema oficial, até se criar um Convênio com a Confederação Nacional das Indústrias (CNI), resultando na atualidade, de o Serviço Nacional de Aprendizagem Industrial (SENAI) e o Serviço Nacional de Aprendizagem Comercial (SENAC) serem responsáveis pela maior rede de escolas de Educação Profissional no Brasil.

Ressalte-se que as escolas do Sistema "S" adotaram na sua gênese uma pedagogia voltada para os interesses do capital. Como isso foi constituído? Através 
do Decreto 4.048/42 ao materializar cursos para aprendizes e operários das empresas. Desde a sua origem, o Sistema "S" apresentava contradições como a sua subordinação ao Ministério da Educação (MEC) e também ao Ministério do Trabalho, resultando em 1971, no Regime Militar, da promulgação de uma lei em que se estabelecia uma equivalência dos cursos do SENAI aos do ensino regular oferecido pelo Estado.

Ao adotar tal equivalência, o governo promovia um aumento na escolarização de segundo grau sem, no entanto, aumentar as despesas com verbas nesse nível de escolaridade. E mais, ao aceitar o SENAl como órgão representativo da educação profissionalizante, os empresários ficavam desobrigados a quaisquer ações e contribuição ao Estado e aos órgãos representativos das indústrias. Ressalte-se que o presidente Vargas recebeu dois projetos de regulamentação do ensino profissional: um do MEC e outro do Ministério do Trabalho, dando prioridade ao do Ministério do Trabalho que era a criação do SENAI, oficializando-o em 1942.3.

Capanema, então Ministro da Educação do Governo Vargas, queria criar um órgão federal para administrar o sistema de ensino industrial, incluindo o financiamento do Estado nos custos através da Lei Orgânica do Ensino Industrial que tentava levar a contento uma formação humana aos trabalhadores através da inclusão de disciplinas de cultura geral; os industriais, por sua vez, queriam, mediante o Sistema "S", autonomia pedagógica e fiscal em troca da manutenção total dos custos com o ensino.

Mas o Decreto-Lei, sob a tutela do Governo Vargas, cria o SENAI e deixa-o autônomo em relação ao Ministério da Educação e ao Estado, colhendo os fundos para a sua manutenção, além dos privilégios de isenções de impostos. Embora Capanema guardasse nas suas defesas discriminações no que se refere à relação entre educação propedêutica e profissional, ele defendia uma formação humana, cívica e moral para o trabalhador, fazendo sérias críticas a forma como o Sistema "S" foi se consolidando numa concepção de trabalho voltada apenas para a instrumentalização prática sem uma preocupação teórica.

Nesse contexto, surge o Instituto de Organização Racional do Trabalho (IDORT), entidade criada pelos empresários como forma de trazer para o debate a reorganização da Educação Profissional no Brasil. Como base pedagógica, o IDORT, em seu projeto, inculcava na criança as possibilidades, mediante o trabalho, de sobrevivência na sociedade capitalista.

Avançando um pouco, já na década de 1950, as escolas técnicas industriais sofreram uma crise, considerando a falta de autonomia, já que, todas as providências dependiam de Portarias não havendo mobilidade nas verbas nem sobras de recursos. Além disso, ocorreu um número enorme de evasão ocasionado por um alto índice de reprovação que, por sua vez, era em decorrência da própria precariedade da formação oferecida: insuficiência dos equipamentos; corpo docente improvisado; carência de uma metodologia adequada. 
Por tudo isso e com a internacionalização da economia, em 1954, o então Ministério da Educação promoveu a I Mesa Redonda Brasileira de Educação Industrial onde se defendeu a autonomia administrativa técnica das escolas industriais da rede federal, além da adequação dos cursos e as demandas da economia. Com a Lei de Diretrizes e Base (LDB) n.5.692/71, há uma ampliação nos anos de estudo para primeiro e segundo graus com a profissionalização integrada numa tentativa de eliminar o dualismo entre ensino técnico e propedêutico, o que não significou a democratização do acesso ao Ensino Superior. Um exemplo disso refere-se ao dado de que as escolas particulares reforçavam o ensino propedêutico preparando os seus alunos para o vestibular e, na esfera pública, a preocupação precípua era atender às demandas do mercado de trabalho em que o caráter universal da educação ficava subordinado aos interesses técnicos. Uma questão se impôs: como ressignificar uma história de Educação Profissional brasileira sempre pautada na dualidade entre teoria e prática, entre trabalho braçal e intelectual?

Nas décadas de 1980 e 1990 ocorreram mudanças significativas no processo técnico e organizacional de trabalho ocasionando reformas na Educação Profissional assentadas nas novas demandas de tecnologias modernas baseadas na microeletrônica. A materialização disso está no Plano Nacional de Qualificação do Trabalhador (PLANFOR) e do Programa de Expansão da Educação Profissional (PROEP). Mas o que se configurou, sobretudo na década de 1990, foi um retrocesso considerando o Decreto n. 2.208/97 que concebeu o dualismo entre o ensino propedêutico e o técnico, mostrando um afastamento das políticas sociais da educação, ao tempo que se alinhou aos interesses do capital privado internacional.

Além disso, ocorreu uma privatização da educação a partir do momento que decretos vetavam a ampliação da rede federal atrelando à Portaria do MEC 646/1997 que limitava a oferta de ensino médio nas instituições federais, de modo que as escolas não poderiam oferecer mais do que $50 \%$ para a modalidade propedêutica, induzindo a abertura de cursos exclusivamente profissionalizantes. Para se ter uma ideia, em 1999, 3.948 instituições ofertavam a Educação Profissional, sendo que 67\% dessas pertenciam a iniciativa privada. No mesmo caminho, a Portaria n. 646/97 determinou que a partir de 1998 a oferta de vagas de cada instituição federal no ensino médio corresponderia a no máximo $50 \%$ das vagas oferecidas nos cursos técnicos de nível médio. Ademais, a Rede Federal teve sua expansão limitada.

$\mathrm{Na}$ era Lula-Dilma, a Educação Profissional começou a ser problematizada pelo Decreto n. 5.154/04, possibilitando a integração do ensino propedêutico ao ensino técnico, em que se retomou uma discussão sobre a educação politécnica entendida como superação da dicotomia entre trabalho manual e trabalho intelectual. Ressalte-se que fazer uma mudança via decreto guarda contradições por não trazer mudanças estruturais. Naquele momento a questão era a necessidade de uma revisão global da LDB - 9395/96 considerando que a aprovação do Decreto n. 5.154/04 trouxe um estímulo à integração curricular, mas não trouxe a garantia de sua implementação (FRIGOTTO; CIAVATTA;RAMOS, 2012). Ainda na era Lula-Dilma, ocorreu a concretização de um plano de expansão consolidado pela Lei n. 11.892/08 que institui a Rede Federal de Educação Profissional tendo como prioridade a integração e 
também a verticalização materializada na implantação do Ensino Médio até a PósGraduação Stricto Sensu.

Nesse contexto histórico, chamo a atenção para uma questão sobre a Educação Profissional e sua relação com a Lei n. 11.892/08 que consolida a Rede Federal. Tal questão se refere aos desafios implicados na modalidade integrada no Ensino Médio, levando em conta um percurso histórico de negação da integração politécnica no cenário brasileiro. Concordamos com Gramsci (1968) quando defende a escola única inicial de cultura geral humanista e formativa, equilibrando de forma equânime o desenvolvimento para o trabalho manual e o desenvolvimento das capacidades de trabalho intelectual. Mas levar a contento a unidade da formação geral com o mundo do trabalho é um desafio, sobremaneira, se considerarmos as condições históricas e sociais da realidade brasileira.

\section{EDUCAÇÃO PROFISSIONAL E ENSINO MÉDIO: DESAFIOS DA INTEGRAÇÃO}

Não é de hoje que diferentes estudos (KUENZER, 1988; BATISTA, MÜLLER, 2003; FRIGOTTO, CIAVATTA, RAMOS, 2012) apresentam problematizações referentes à desintegração entre as disciplinas propedêuticas e técnicas no Ensino Médio mostrando a importância da formação humana e intelectual daqueles que estão sendo preparados na esfera técnica para o mundo do trabalho. Conforme vimos, na Era Lula-Dilma ocorreu a integração do ensino propedêutico ao ensino técnico com a revogação do Decreto n. 2.208/97, embora o Decreto 5.154/04 tenha presentificado contradições.

Nesse cenário, chama-se a atenção para Plano de Desenvolvimento da Educação (PDE) que, em 2007, propõe uma seção especificamente dedicada à articulação entre a Educação Profissional e o Ensino Médio. Antes disso, em 2003, dois seminários foram decisivos para essa articulação: "Ensino Médio: Construção Política"; "Seminário Nacional de Educação Profissional: Concepções, experiências, problemas e propostas". Nesses seminários ficou evidente que o debate se ancorou em duas vertentes: a primeira ancorada nos princípios do Decreto n. 2.208/97 e outra que trazia a construção de um projeto em que superasse a dualidade entre formação específica e formação geral. A última como uma necessidade conjuntural e como possibilidade para que os filhos dos trabalhadores acessassem, também, ao Ensino Superior.

Embora a LDB (9.394/96) em seus artigos 36, 39 e 40 sinalizarem uma Educação Profissional integrada às diferentes formas de educação, do trabalho, da ciência e da tecnologia, vimos, no percurso histórico, que a Educação Profissional teve sua origem numa perspectiva assistencialista se afirmando uma formação técnica para o trabalho na indústria sem dar acesso ao ensino superior, já que, a organização curricular não tinha disciplinas propedêuticas. Uma perspectiva que acabou por não garantir a função precípua da escola pública brasileira ao longo dos 
séculos, que é conceber a educação ao mundo do trabalho, da cultura e da ciência como um direito social e subjetivo vinculado a todas as esferas e dimensões da vida.

O que ocorreu, de fato, foi a expansão do ensino privado que garantia uma formação para as ciências, letras e artes visando o atendimento de uma parcela da sociedade. Expansão que resultou na busca pela escola privada uma vez que garantia a continuação dos estudos no Ensino Superior, alimentando um processo de desvalorização das escolas públicas, em especial, daquelas que ofereciam o ensino técnico. O próprio texto da LDB (9394/96) é ambíguo no que se refere ao Ensino Médio e Educação Profissional, pois há uma dicotomia quando o Ensino Médio materializase no Capítulo II, no âmbito da Educação Básica, enquanto a Educação Profissional está em outro, Capítulo III, constituída por três artigos. Mesmo que a LDB tenha potencializado a dualidade entre o Ensino Médio Básico e a Educação Profissional, uma nova configuração para integração ou o rompimento de tal dualidade se deu com o Decreto n. 5154/2004 em articulação com diferentes documentos construídos pela Secretaria de Educação Profissional e Tecnológica (SETEC), resultados de um grande debate durante o ano de 2003.

Romper com a dualidade implica uma possibilidade para os filhos da classe trabalhadora ingressarem na Rede Federal de Educação Profissional Tecnológica tendo uma formação integral. A integração vista como uma política pública mediante algumas ações cooperadas, sobretudo, uma articulação entre diferentes ministérios e entre os sistemas estaduais e municipais. Ou como afirma Gramsci (1968), uma proposta de educação que crie os valores fundamentais do humanismo, a autodisciplina intelectual e a autonomia necessárias a uma posterior especialização de caráter científico e prático-produtivo, o que implica relacionar, não só na escola como também na vida social, o trabalho intelectual e o trabalho industrial.

Sobre as concepções e os princípios da integração, temos o Documento-Base "Educação Profissional Técnica de Nível Médio Integrada ao Ensino Médio" que se filia a uma concepção de formação humana considerando todas as dimensões da vida no processo educativo: trabalho, ciência, cultura e tecnologia. O que seria integrar para o documento? Tratar a educação como uma totalidade social, das partes no todo ou da unidade no diverso. Para isso, defende os pressupostos do currículo integrado uma vez que desenvolve o processo de ensino-aprendizagem de modo que os conceitos sejam apreendidos como sistema de relações de uma totalidade concreta. Já o conceito de trabalho é visto sob a dimensão ontológica que é o ponto de partida para a produção de conhecimentos e de cultura pelos grupos sociais.

O conhecimento, dessa forma, é uma ação do pensamento pela qual se apreende e se representa as relações que constituem e estruturam a realidade, sendo a teoria o elevado plano conceitual desse pensamento. A cultura, por sua vez, é compreendida como norma, como expressão e como organização político-econômica da sociedade, materializando as ideologias que cimentam o bloco social. Ou seja, cultura como o conjunto de representações, símbolos, significados construídos pelo tecido social num processo dinâmico de socialização. Entender essa cultura através 
de um processo reflexivo no espaço da sala de aula é o princípio de uma formação integrada (BRASIL, 2007).

A base dessas ideias está numa perspectiva histórico-materialista em que o trabalho é entendido como a primeira mediação entre o ser humano e a realidade material e social, ou seja, uma visão ontológica pela qual a pessoa produz sua própria existência na relação com a natureza e com outras pessoas produzindo conhecimentos. Para Frigotto (2012), a concepção humana ontológica e ontocriativa está implicada ao sentido de propriedade que se refere ao intercâmbio material entre o ser humano e a natureza para manter a vida humana; o que corresponde às necessidades de sua vida cultural, social, estética, simbólica, lúdica e afetiva. Trabalho, compreendido, também, como processo histórico que, no Capitalismo, se transforma em trabalho assalariado de modo a ser uma categoria econômica e práxis produtiva, o que justifica a formação específica para o exercício de profissões, da força de trabalho do Capitalismo. Não se pode perder de vista que o trabalho no sentido ontológico em integração com o conceito de trabalho para a profissionalidade, deve nortear a base unitária do Ensino Médio numa dinâmica de organização curricular em que se considere a sistematização de disciplinas básicas e específicas, da interdependência entre teoria e prática.

Ademais, há o conceito de pesquisa compreendido como princípio educativo que se presentifica numa prática pedagógica em que o aluno tenha inquietudes diante das informações e saberes que estão a sua volta, do senso comum aos científicos, o que potencializa a relação ensino e pesquisa para o desenvolvimento das capacidades de interpretar, analisar, criticar, refletir, rejeitar ideias fechadas, aprender, buscar soluções e propor alternativas (BRASIL, 2007).

Para dar conta disso, a ideia é partir da integração entre conhecimentos gerais e específicos de modo a garantir uma interdisciplinaridade como princípio organizador do currículo e como método de ensino-aprendizagem numa inter-relação entre área profissional e área propedêutica. Além disso, uma construção de um projeto políticopedagógico integrado como construção coletiva se a comunidade compreender como pertinente para implantá-lo. Acredito na ideia de educação integrada que se volte para a formação humana a fim de garantir ao jovem trabalhador uma trajetória formativa para que ele leia as condições de produção e as relações sociais subjacentes a todos os fenômenos.

Diante das considerações acima, problematizo: como a modalidade integrada está se materializando na Rede Federal de Ensino? Quais as implicações do currículo integrado nessa modalidade? É possível, de fato, implicar as disciplinas propedêuticas no processo de formação para o mundo do trabalho? Os estudantes estão tendo oportunidade para ingressar na Universidade através da formação geral promovida pela Rede Federal? Como os Institutos Federais estão enfrentando os desafios levando em conta as políticas afirmativas na modalidade integrada? Questões que trazem subjacentes propostas para que pesquisadores possam se implicar e compreender como está se presentificando no "chão" dos Institutos Federais a modalidade integrada se considerarmos um percurso histórico de desintegração e 
negação de uma formação geral para as classes sociais desfavorecidas da sociedade brasileira, conforme vimos na primeira seção deste artigo.

Além disso, tais questões trazem dilemas e contradições. Não tenho a intenção de discutir todas neste artigo, mas chamo a atenção para o desafio de preparar os estudantes para o mundo do trabalho e para o Ensino Superior e vida acadêmica. Historicamente, no Brasil, conforme vimos, são propostas díspares, distantes do ponto de vista significativo e funcional, cuja valoração por parte da sociedade é influenciada por fatores econômicos e ideológicos, tendo como consequência uma situação de conflito de ordem qualitativa, vocacional e paritária, expresso na desigualdade de acesso a oportunidades funcionais e acadêmicas, distorção de valores como ética, cidadania e coletividade (ARAÚJO, 2005; CASTRO, 2008). Nesse contexto, trago, também, o conceito de verticalização promulgado na Lei no 11.892, de 29 de dezembro de 2008, que instituiu a Rede Federal de Educação Profissional, Científica e Tecnológica e criou os Institutos Federais de Educação, Ciência e Tecnologia, abrindo uma nova perspectiva na Educação Profissional integrada, significativa e relevante aos desafios da sociedade brasileira contemporânea. Sobre isso vejamos o Artigo 60 da referida Lei:

I - ofertar educação profissional e tecnológica, em todos os seus níveis e modalidades, formando e qualificando cidadãos com vistas na atuação profissional nos diversos setores da economia, com ênfase no desenvolvimento socioeconômico local, regional e nacional;

II - desenvolver a educação profissional e tecnológica como processo educativo e investigativo de geração e adaptação de soluções técnicas e tecnológicas às demandas sociais e peculiaridades regionais;

III - promover a integração e a verticalização da educação básica à educação profissional e educação superior, otimizando a infraestrutura física, os quadros de pessoal e os recursos de gestão; IV - orientar sua oferta formativa em benefício da consolidação e fortalecimento dos arranjos produtivos, sociais e culturais locais, identificados com base no mapeamento das potencialidades de desenvolvimento socioeconômico e cultural no âmbito de atuação do Instituto Federal [...] (BRASIL, 2008).

Fica evidente a preocupação em integrar o Ensino Médio ao tecnológico, integrar as modalidades de ensino mediante estratégias de permanência que visem a continuidade dos estudos, a verticalização da educação básica à profissional e superior, atendendo às necessidades formativas do educando, cidadão, profissional, necessário ao desenvolvimento social e econômico do país. Uma questão se impõe: é possível garantir isso?

Em "Pesquisa Nacional de Egressos dos Cursos Técnicos da Rede Federal de Educação Profissional e Tecnológica”, realizada entre os anos de 2003 a 2007, há um panorama sobre a formação técnica de nível médio ofertada pelas instituições da 
Rede Federal em relação a três variáveis: a empregabilidade dos egressos; a continuidade dos estudos após a conclusão do curso técnico; e a avaliação pelos egressos quanto à formação técnica recebida. Embora essa pesquisa não se refira especificamente à integração, traz dados sobre a importância da Rede Federal para a inserção e a consolidação dos estudantes no mundo do trabalho, mostrando a relevância da Educação Profissional para aqueles que querem continuar os estudos, seja no Ensino Superior ou em outros cursos técnicos. A pesquisa foi realizada em âmbito nacional junto a 153 instituições e com egressos mediante questionário, entrevista e grupo focal. O primeiro dado mostra que $72 \%$ dos egressos estão inseridos no mercado de trabalho e $44 \%$ atuam na área do curso técnico de formação, ao passo que $27 \%$ e $59 \%$ mostraram estar muito satisfeitos e satisfeitos, respectivamente, com a sua situação profissional. A carga horária de trabalho é de 40h semanais, o que explica 38\%, apenas, dos entrevistados trabalharem e estudarem simultaneamente. Ainda assim, estão inseridos no Ensino Superior, o que evidencia a preocupação com a escolaridade para a empregabilidade. Concluo, desse modo, a importância da formação técnica oferecida aos jovens e adultos da Rede Federal de Educação Profissional levando em conta o mundo do trabalho e também nas possibilidades de continuidade dos estudos bem como permanência e mobilidade no trabalho.

Com isso, a ideia é que as disciplinas técnicas se consolidem e estejam integradas às disciplinas da formação geral superando a perspectiva idealista de separar instrução de educação (GRAMSCI, 1968). Quando se pensa na relação entre trabalho e educação, há uma possibilidade de a Educação Profissional se tornar para o trabalhador ou o jovem o direito à cidadania implicada no seu poder de negociação no mercado de trabalho, afinal operar uma máquina não pode prescindir de qualquer esforço intelectual. Para isso, a formação humana, crítica e política materializada, a meu ver, nas disciplinas propedêuticas, constituem-se como superação do pragmatismo, ou seja, a superação do ser humano dividido entre a ação de executar e a ação de pensar.

Nesses possíveis, configura-se o "calcanhar de Aquiles": promover uma organização curricular em que a ciência, a cultura, a tecnologia e o trabalho estejam integrados, conforme o Decreto n. 5.154/04 e a Lei 11.892/08. Porém, em análise feita sobre o Projeto Pedagógico Institucional da Rede Federal da Bahia, vimos que o "como" da efetivação curricular integrada ainda está distante das práticas pedagógicas e, em alguns momentos de estudo sobre o documento constatei que, no campo empírico, os estudantes do Curso Integrado têm uma resistência à área técnica recaindo no dado de que eles têm buscado o Instituto a garantia de uma vaga na Universidade. Nada de ilegítimo nisso haja vista termos uma história no campo legislativo de negação aos jovens oriundos de determinadas classes sociais o acesso ao Ensino Superior. Dessa forma, uma questão que exponho é o fato de isso não estar evidenciado também como objetivo da Rede Federal, ou seja, um espaço de preparação para a prova do Exame Nacional do Ensino Médio (ENEM). Nesse âmbito, sugere-se pesquisas nacionais em que se analise o número de estudantes da Rede 
Federal que fazem o exame ao passo que relacione com dados sobre o mundo do trabalho sob a ótica desses jovens.

Em síntese, acredito que o desafio seja a construção de uma organização curricular integrada que considere as vozes dos próprios estudantes:

[...] os alunos trabalhadores procuram a escola para melhor compreender o mundo em que vivem, para conhecer, para entender as transformações causadas na sociedade pelo avanço da ciência e da tecnologia, para aprender novas formas de comunicação, para conhecer e participar de outras experiências sociais e culturais (KUENZER, 1996, p. 101).

Para a autora, o pressuposto é a formação de um novo intelectual tendo o trabalho como princípio educativo a caminho da superação da cisão entre escola clássica e escola profissionalizante envolvendo a cientifização de todo e qualquer trabalho prático.

Conforme mencionei, a minha intenção foi problematizar o ensino integrado levando em conta nuances históricas, legais e sociais no contexto brasileiro sem, no entanto, dar respostas encerradas as questões levantadas. Mesmo porque, o Decreto n. 5.154/04 e a Lei 11.892/08 são recentes, o que requer pesquisas que compreendam e elucidem o modo como o ensino médio integrado tem se materializado na prática pedagógica. Para isso, investigações que deem conta de uma "escuta sensível" dos atores envolvidos: docentes, discentes, egressos, gestores e pais. Dessa forma, teremos possibilidade de construir inferências concretas a partir do campo empírico que, de fato, nortearão os caminhos da Rede Federal de Educação Profissional no Brasil.

\section{CONSIDERAÇÕES FINAIS}

Com o exposto, este artigo se presentifica como um pontapé para que outros estudos se dediquem a compreender, sob a voz de discentes, docentes, gestores e pais, o Ensino Médio Integrado de modo a analisar, nesses 12 anos, como está funcionando a inter-relação entre disciplinas técnicas e propedêuticas na prática pedagógica, sobretudo. Há muitas defesas sobre isso, mas é importante saber como tudo isso está se concretizando na sala de aula. Entre as defesas e as práticas dessa perspectiva, destaco, em livro meu, "Manuscritos Feministas-Femininos", que traz experiências com a arte literária como formadora humana e cultural de jovens profissionais. Defendo, por meio das indicações de Gramsci (1968) sobre a Escola Unitária, que qualquer espaço de ensino deve garantir uma formação humanista e intelectual ao passo que forma para o mundo do trabalho concretizada na formação profissional. 


\section{REFERÊNCIAS}

BATISTA, E. L.; MÜLLER, M. T. A Educação Profissional no Brasil. Campinas, SP: Editora Alínea, 2003.

BRASIL. Lei n. 11.892, de 29 de dezembro de 2008. Institui a Rede Federal de Educação Profissional, Científica e Tecnológica, cria os Institutos Federais de Educação, Ciência e Tecnologia e dá outras providências. Diário Oficial da União. Brasília. 30 dez. 2008. Seção 1, p. 1.

BRASIL. Ministério da Educação. Documento Base da Educação Profissional Técnica de Nível Médio Integrada ao Ensino Médio. Brasília. MEC/Setec, set 2007.

FRIGOTTO, G.; CIAVATTA, M.; RAMOS, M. (Org.). Ensino médio integrado: concepção e contradições. São Paulo: Cortez, 2012.

GRAMSCI, Antonio. Os intelectuais e a organização da cultura. Tradução Carlos Nelson Coutinho. Rio de Janeiro: Civilização Brasileira, 1968.

KUENZER, Acácia. Ensino de segundo grau: o trabalho como principio educativo. São Paulo: Cortez, 1988. 